\title{
Material sensible. Un proyecto de fotografía participativa que muestra la experiencia de personas que han sufrido abusos sexuales en la infancia.
}




\section{SENSITIVE MATERIAL. A PARTICIPATORY PHOTOGRAPHY PROJECT THAT SHOWCASES THE EXPERIENCE OF PEOPLE WHO HAVE SUFFERED SEXUAL ABUSE IN CHILDHOOD.}

\section{ABSTRACT}

Material sensible is a participatory photography project with people who have been sexually abused in their childhood and receive therapeutic support. The project is based on the Punt de Vista methodology, using photography as a tool for personal transformation and social inclusion, aimed at groups and people at risk of social vulnerability, which are not visible in predominant discourses. Through accompaniment and immersion in a creative process that uses intimacy as a reference, it connects image, memory, identity, everyday life and representation. Each participant recovers emotions and fragments of their personal history - often silenced - by reconstructing their own visual narrative. The project ends with a collective exhibition resulting from the creative process of each participant, which helps to strengthen the identity, generate new stories and raise awareness of an unspoken subject such as child sexual abuse.

\section{Keywords}

participatory photography; sexual abuse; intimacy; community arts; creative process; identity story. 
MATERIAL SENSIBLE. UN PROYECTO DE FOTOGRAFÍA

PARTICIPATIVA QUE MUESTRA LA EXPERIENCIA DE

PERSONAS QUE HAN SUFRIDO ABUSOS SEXUALES EN LA

INFANCIA.

RESUMEN

Material sensible es un proyecto de fotografía participativa con personas que han sufrido abusos sexuales en la infancia y que están recibiendo apoyo terapéutico. El proyecto está basado en la metodología Punt de Vista que utiliza la fotografía como herramienta de transformación personal e inclusión social, dirigida a colectivos y personas en riesgo de vulnerabilidad social, poco visibles en discursos hegemónicos. A través del acompañamiento y la inmersión en un proceso creativo que utiliza la intimidad como fuente de referencia, se articulan relaciones entre imagen, memoria, identidad, cotidianidad y representación. Cada participante recupera emociones y fragmentos de su historia personal -a menudo silenciada- reconstruyendo una narración visual propia. El proyecto finaliza con una exposición colectiva fruto del proceso de creación de cada participante, que ayuda a reforzar la identidad, generar nuevos relatos y concienciar a la sociedad sobre un tema tabú como es el abuso sexual infantil.

\section{Palabras Clave}

fotografía participativa; abusos sexuales; intimidad; arte comunitario; proceso creativo; relato identitario. 
Siempre me ha llamado la atención la facilidad con la que reducimos una persona a unos pocos datos. Una persona es una multitud de fragmentos, su vida no es una historia, sino un mapa o, mejor, una retícula o un rizoma que ofrece itinerarios diversos, cada uno de los cuales daría pie, si lo sugiriésemos, a construir una historia distinta a otras. (Maillard, 2019, p. 69)

\section{INTRODUCCIÓN}

El presente artículo analiza desde una doble vertiente cómo la fotografía participativa puede ayudar a crear y difundir historias de hombres y mujeres que han vivido algún tipo de abuso sexual en la infancia, y cómo la creación artística puede sensibilizar a la sociedad a través de estos relatos identitarios narrados en primera persona. El proceso incluye el contacto, la sensibilización y la concienciación tanto a nivel individual como grupal de la realidad vivida desde el momento presente por cada participante y la resignificación de esta, al articularla a través una narración visual propia.

Material sensible es el proyecto de fotografía participativa impulsado desde el Área de Educación de la Fundación Photographic Social Vision (PSV), realizado con personas que reciben ayuda terapéutica en la Fundación Vicki Bernadet (FVB) y que, de manera voluntaria, han querido participar en un proceso de creación artística que acompaña, enriquece y complementa su proceso terapéutico. Durante seis meses, el grupo de participantes ha utilizado la fotografía como medio para reconstruir su relato, ampliar su identidad y culminar el proceso compartiéndolo en primera persona a través de una exposición.

El proyecto utiliza la metodología Punt de Vista creada desde el Área de Educación de la fundación PSV basada en 16 años de experiencia con colectivos en riesgo, en el que se utiliza la fotografía para potenciar la transformación personal y la inclusión social. El presente artículo analiza las dos ediciones de Material sensible llevadas a cabo en 2017 y 2019. Ambos proyectos han dado fruto a dos exposiciones realizadas en Barcelona, junto con su campaña de comunicación. El autorretrato de N.J. (ver Fig.1) creado en la primera edición de Material sensible ha sido una de las imágenes centrales a la hora de difundir el proyecto en su fase final expositiva, con el ánimo de ayudar a sensibilizar a la sociedad sobre una temática tabú como es el abuso sexual infantil.

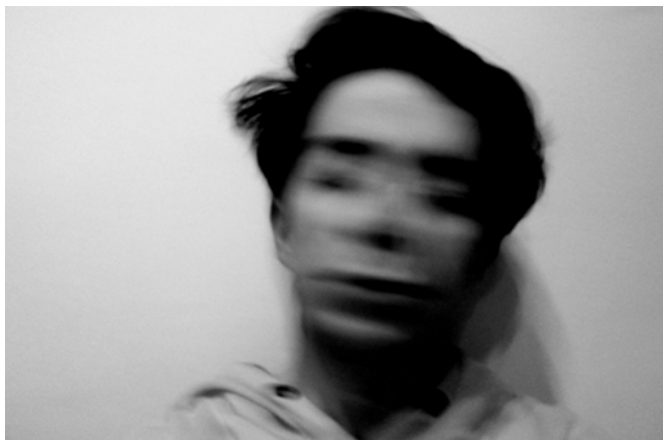

Figura 1. Foto de N.J. expuesta en la primera edición de Material sensible, 2017 


\section{CONTEXTO}

2.1 EQUIPO Y ENTIDADES RELACIONADAS

Photographic Social Vision ${ }^{1}$ (PSV) es una entidad de referencia con sede en Barcelona comprometida en divulgar y potenciar el valor social de la fotografía documental y el fotoperiodismo. Desde su Área de Educación, se utiliza la educación visual como herramienta de sensibilización y transformación social organizando actividades y talleres fotográficos para todos los públicos. Punt de Vista, es la apuesta del Área de Educación de PSV para usar la fotografía como herramienta de expresión, transformación e inclusión social empleando una metodología participativa propia. Un proyecto que busca documentar realidades a través de la mirada de quien las vive, personas que no siempre tienen acceso a la fotografía o al lenguaje visual y suelen tener poca visibilidad en la sociedad. Desde 2004 hasta la actualidad, se han articulado más de 14 proyectos con distintos colectivos e individuos, muchos de ellos en situaciones de vulnerabilidad social (jóvenes migrantes, personas diagnosticadas con algún problema de salud mental y gente mayor, entre otras).

La Fundación Vicki Bernadet ${ }^{2}$ (FVB) trabaja desde 1997 en la atención integral, prevención y sensibilización de los abusos sexuales a menores cometidos en el ámbito familiar y el entorno de confianza del niño o niña persiguiendo un doble objetivo: romper el "círculo de silencio" para que las víctimas dejen de avergonzarse, de sentirse culpables y encuentren la fuerza suficiente para pedir ayuda, y que la sociedad reconozca su existencia y emplee los medios necesarios para prevenirlo, identificarlo a tiempo y tratarlo adecuadamente.

La primera colaboración entre PSV y FVB se produjo en 2002, cuando PSV realizó un reportaje de investigación con testimonios que habían sufrido abusos sexuales en la infancia, y se publicó en el Magazine de La Vanguardia ${ }^{3}$. El impacto social que generó el artículo ayudó a convertir a la FVB en una entidad de referencia nacional. Desde entonces, Silvia Omedes, directora de PSV, es miembro activo del patronato de FVB.

De febrero a julio de 2017 se creó desde el Área de Educación de PSV con el soporte del equipo terapéutico de FVB, la primera experiencia de formación y creación conjunta que finalizó con la exposición de la primera edición de Material sensible en la galería Projeckteria [Art Gallery]. El éxito rotundo de este primer proyecto y la voluntad de profundizar y afinar la metodología utilizada impulsó a crear la segunda edición con un nuevo grupo de personas que realizaron el proyecto entre marzo y noviembre de 2019, y finalizó también con una exposición, en la galería Chiquita Room.

A nivel de equipo, la autora del artículo, junto con Alice Monteil, han dirigido, diseñado y facilitado el proyecto. Ambas llevan una trayectoria juntas diseñando e impartiendo proyectos Punt de Vista y creando su metodología, basada en una idea original de Caro García. Material sensible ha contado también con la colaboración profesional de Silvia Omedes, Vicki Bernadet, Heléna Vélez, Inés Casals, Ana de Quadras, Laura González, Teresa Vallbona y Luís Ceprián. Un proyecto que ha sido supervisado y acompañado durante todas las fases de desarrollo, por las psicólogas de la fundación Vicki Bernadet, Pilar Polo y Núria Grau. Las participantes del taller 
y autoras ${ }^{4}$ de las obras expuestas son L. R., Marga, Marta Tomeo Urango, N. J., N. L. P. y Rosa Rigall Desplans en la primera exposición, así como Bea Baños Cairat, Beatriz Burgos, Isha Normahomed, Mireia M. y Momo en la segunda.

\subsection{CONTEXTO HISTÓRICO}

La historia de la violencia hacia los menores se remonta como mínimo, a la antigua Grecia, donde eran prácticas habituales el abandono, las castraciones y los sacrificios rituales de niños y niñas. El psicoanalista Lloyd de Mause recopiló en su investigación acerca de la historia de la infancia las diversas formas de relación entre padres e hijos, y como estas se fueron transformando a lo largo de distintos contextos históricos (De Mause, 1974). De Mause, evidencia cómo la necesidad de proteger, cuidar y tratar bien a los niños es un concepto moderno, que ha ido moldeándose a lo largo de los siglos.

Si buscamos definiciones sobre abuso sexual tenemos que remontarnos a mediados del siglo XIX, cuando Ambroise Tardieu, profesor de medicina legal de la Facultad de Medicina de París, describió los primeros casos de abuso infantil en su estudio forense sobre delitos sexuales "Étude Médico-Légale sur les Attentats aux Moeurs" (Tardieu, 1878). Dos siglos más tarde, el pediatra C. Henry Kempe junto con su equipo médico, identificó y reconoció el maltrato infantil en su artículo "El síndrome del niño golpeado o maltratado" (Kempe et al., 1962), donde encontramos la primera definición precisa sobre el abuso sexual infantil.

En su "Informe sobre Abuso sexual infantil" Unicef nos recuerda que "la historia de la violencia hacia la infancia es antigua y moderna a la vez: antigua si seguimos sus rastros hacia atrás, pero moderna si la pensamos en términos de la categorización concreta del problema" (Baita y Moreno, 2015, p.15).

A nivel legal, Vicki Bernadet nos recuerda en su conferencia "La confianza educada" (Bernadet, 2016) el paradigmático caso de Mary Ellen que abrió un proceso judicial en 1874 jamás visto en la historia de la protección de la infancia: una niña maltratada es amparada por la ley norteamericana gracias a la invocación de una ley de protección de animales. Durante el juicio, su abogado alegó que "Mary Ellen pertenecía al mundo animal, aunque racional" (Bernadet, 2016). Hasta entonces, no existe en la historia occidental, ninguna ley que contemplara el abuso o maltrato a niños y niñas.

El primer documento en el que se reconoció y afirmó la existencia de derechos específicos de los niños, así como la responsabilidad de los adultos hacia ellos, fue aprobado por la Sociedad de Naciones en la Declaración de Ginebra de $1924^{5}$. Pero, no fue hasta el 20 de noviembre de 1959, cuando se elaboró una segunda Declaración de los Derechos del Niño ${ }^{6}$ que incluyó 10 principios. Esta Declaración no fue suficiente para proteger los derechos de la infancia ya que, legalmente, no tuvo carácter obligatorio. Es por eso que, en 1978, el Gobierno de Polonia presentó a las Naciones Unidas la versión provisional de la Convención sobre los Derechos del

\footnotetext{
4 En el presente artículo se usa el femenino para hablar de las personas que han participado al taller, ya que ambos grupos están integrados mayoritariamente por mujeres.

5 Dos décadas más tarde, tras finalizarse la segunda Guerra Mundial, las Naciones Unidas (ONU) aprobaron en 1948 la Declaración Universal de los Derechos Humanos.

6 Más información sobre el texto completo de la Declaración de los Derechos del Niño del 20 de noviembre de 1959 traducida al español por Humanium: https://www.humanium.org/es/declaracion-1959/
} 
Niño que se aprobó con carácter obligatorio para los países que la ratificasen el 20 de noviembre de $1989^{7}$, texto que se convirtió en ley el 1990.

\subsection{DATOS ACTUALES}

Las cifras hablan por sí solas del impacto que tiene el abuso sexual en nuestra sociedad actual: según la campaña de 2010 contra el abuso sexual infantil del Consejo de Europa, se estima que al menos 1 de cada 5 niños/as han sufrido o sufrirán algún tipo de abuso sexual antes de los 18 años (NCTSN, 2009). Específicamente, en el contexto en el que se ubica este artículo, el estudio publicado por Pereda y Forns entre alumnos y alumnas del curso 2001/2002 de la Universidad de Barcelona, un 15,5\% de varones y un $19 \%$ de las mujeres manifestaron haber sufrido esta experiencia antes de los 13 años de edad (Pereda y Forns, 2007, p.417).

En el artículo "Adolescents who experienced sexual abuse: fears, needs and impediments to disclosure" ${ }^{\prime \prime}$, (Crisma et al., 2004) se analizan los principales impedimentos entre adolescentes para contar a sus familiares el abuso: el miedo a no ser creídos, la vergüenza, y el miedo a causar problemas en la familia. Félix López revela en su estudio realizado para el Ministerio de Asuntos Sociales, que entre el $80-85 \%$ de los casos el abuso es intrafamiliar y en el entorno de confianza, el $60 \%$ no recibirá ningún tipo de ayuda, y el $90 \%$ no lo dirá durante la infancia (López, 1996).

Teniendo en cuenta estas cifras, la psicóloga María Torres advierte que "el abuso infantil es, por tanto, un problema de salud pública que requiere una atención especializada y, sobre todo, de una toma de consciencia por parte de toda la sociedad" (Torres, 2018).

\subsection{CONTEXTO PSICOLÓGICO}

El Abuso Sexual Infantil (ASI) es, en la mayoría de los casos, una experiencia traumática que interfiere en el adecuado desarrollo de la víctima que lo sufre e incide negativamente en su estado físico y psicológico (Echeburúa y Guerricaechevarría, 2000). Las consecuencias que acompañan la vivencia de un abuso son diversas, y en la mayoría de los casos, perduran hasta la edad adulta afectando no solo a la víctima, sino a su entorno y a la sociedad.

La psicóloga María Torres apunta que "la potencia traumática del ASI se basa, principalmente, en la traición de la confianza del niño" (Torres, 2018). Ser víctima de un ASI genera secuelas tan variadas que resulta difícil valorar el impacto traumático que supone haberlas sufrido. Algunas son evidentes y otras más sutiles de identificar dependiendo siempre de cada experiencia subjetiva.

Torres hace hincapié en la invisibilidad de esta problemática ya que los indicadores directos (como lesiones físicas) están muy a menudo ausentes, y es muy difícil reconocerse como víctima. "EI ASI existe, casi siempre, rodeado de silencio, que lo hace más invisible aún (...). Pero, si la persona habla y no le creen, dudan de la veracidad o no le dan el valor suficiente, añade un

7 Texto completo de la Convención sobre los derechos del niño del 20 de noviembre de 1989 traducida al español por UNICEF: https://www.un.org/es/events/childrenday/pdf/derechos.pdf 8 "Adolescentes que sufrieron abusos sexuales: temores, necesidades e impedimentos para la revelación". Traducción de la autora. 
nuevo acto de violencia sobre el niño o el adulto" (Torres, 2018).

Rosa Royo, psicoanalista supervisora de instituciones especializadas en la atención al maltrato y el abuso sexual infanto-juvenil, nos recuerda que:

A pesar de no poder generalizar, se puede asegurar que el ASI posee un alto valor traumático y sus repercusiones aparecen en todos los ámbitos del menor: físico, psíquico y social, dejando al niño en un estado de vulnerabilidad generalizada. Cuando alguien abusa de un menor, abusa de algo más que un cuerpo, toquetea algo más que la piel, incluso aquello que no puede tocarse: los sentimientos, la dignidad, la mente (Royo, 2016, p.10).

Desde esta atención al abuso en singular y a la vivencia que cada persona puede explicar y mostrar, se articula el proceso artístico y creativo que propone Material sensible a través de la fotografía como complemento a la terapia individual.

Haciendo un salto hacia territorios más metafóricos, en su ensayo sobre la creación poética, Chantal Maillard nos recuerda que "cuando las cosas, de por sí movientes, se nombran, adquieren límites, dejan de ser inabarcables y, 'dentro de un orden', entonces, son manejables" (Maillard, 2016, p.12). Nombrar lo silenciado a través de imágenes puede servir para recuperar los límites, los nombres propios, ordenar los recuerdos e identificar cómo se expresan estas vivencias desde la actualidad.

Pero ¿cómo explicar una realidad que se vive en carne propia, y que se oculta hasta la edad adulta en el $90 \%$ de los casos? ¿qué necesidad hay de crear un relato que nombre lo ocurrido desde aquellas personas que lo vivieron?

\subsection{CONTEXTO ARTístico}

En la fase de diseño de Material sensible, previo a su implementación, se han analizado dos tipos de proyectos artísticos: en primer lugar, proyectos relacionados directamente con el ASI y, en segundo lugar, artistas que utilizan la fotografía como herramienta para investigar su identidad, desde una perspectiva íntima y autorreferencial.

Existe una cierta dificultad en identificar ciertos trabajos de artistas relacionados con experiencias de ASI, que utilicen la imagen fija como herramienta de creación, ya que muchas veces esta información no es nombrada de forma explícita por parte de los/las artistas. Un trabajo de referencia realizado en el contexto africano es el proyecto de la fotógrafa Mariella Furrer en el que documenta con una cámara y una grabadora de sonido a 7 víctimas de ASI durante más de 10 años (de 2003 a 2013). Con el fin de explicar las múltiples facetas que afecta el ASI, Furrer incluye en su relato a abusadores y entidades policiales que envuelven a las víctimas. Lo que empezó siendo un reportaje fotográfico, se convirtió en un proyecto documental de larga duración que culminó con la publicación del libro My piece of sky (2014). El libro contiene las imágenes realizadas por la autora, y la trascripción de entrevistas, diarios, dibujos y poesías recopiladas durante el proceso de creación: 
The book presents over 600 pages of photographs, interviews, artwork, journals and poetry that together deliver an unprecedented multi-sensory examination of child sexual abuse: how it impacts on the survivors and their families, the effect on child services professionals, police, prosecutors, and the community at large, and an insight into the perpetrators and their own personal history, among other stories ${ }^{9}$. (Furrer, 2014)

Furrer nos muestra como el ASI puede ser explicado desde lugares muy distintos, con voces que se entrecruzan, pero, sobre todo, uno de los pilares de su proceso de creación del que bebe Material sensible es la interdisciplinariedad, yendo más allá de la imagen fotográfica y abriendo el proceso de creación a otros materiales o técnicas. Algunas participantes del proyecto no solo han utilizado las imágenes que han disparado en su día a día, sino que han incluido en sus creaciones, textos, fotografías de archivo, imágenes del álbum familiar o incluso han incorporado en su diseño expositivo objetos o materiales que las ocultaran parcialmente. En la misma línea creativa, en Europa, la fotógrafa alemana Sina Niemeyer, también incluye en Für mich (2018) imágenes, textos, fotografías familiares, autorretratos y objetos encontrados, y puntualmente, interviene directamente en algunas imágenes, rasgándolas o cortándolas (ver Fig. 2) aumentado la carga simbólica de estas. Niemeyer presenta en formato expositivo y de fotolibro su experiencia íntima de ASI:

Für mich is the artist's autobiographic story of sexual abuse. Sina Olsson combines different artistic strategies like photography, writing, graphic design and multiple layers of material such as old family pictures, destroyed images, self-portraits and found objects $^{10}$. (Niemeyer, 2018).

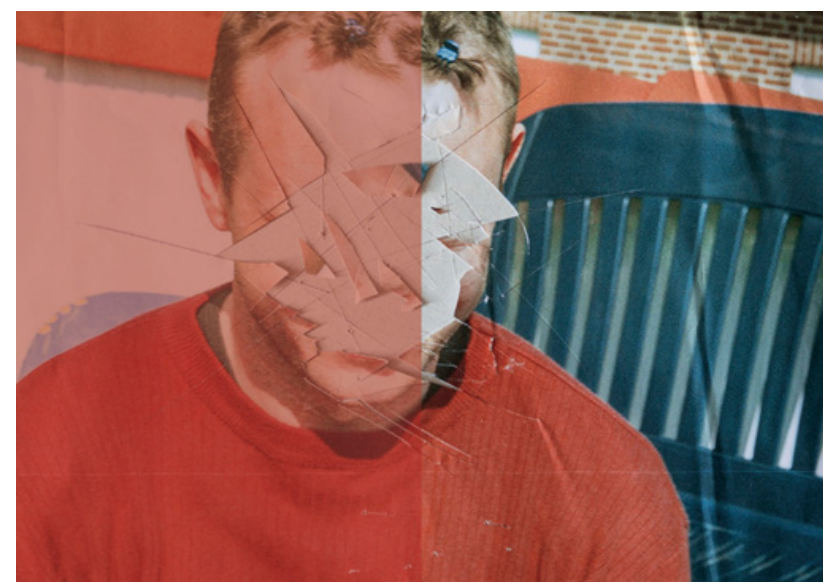

Figura 2. Foto de Sina Niemeyer, de la serie Für mich, 2018.

Fuente: http://www.sinaniemeyer.com/fuer-mich (C) Sina Niemeyer

\footnotetext{
9 El libro presenta más de 600 páginas de fotografías, entrevistas, obras de arte, revistas y poesía que en conjunto ofrecen un examen multisensorial sin precedentes del abuso sexual infantil: cómo afecta a los sobrevivientes y a sus familias, el efecto que causa en los profesionales de los servicios de atención a la infancia, la policía, los fiscales y la comunidad en general, y una visión de los abusadores y su propia historia personal, entre otras historias. Traducción de la autora.

10 "Für mich" es la historia autobiográfica de la artista sobre el abuso sexual. Sina Olsson combina diferentes estrategias artísticas como la fotografía, la escritura, el diseño gráfico y múltiples capas de materiales, como viejas imágenes familiares, imágenes destruidas, autorretratos y objetos encontrados. Traducción de la autora. Para leer el texto completo de Niemeyer ver: https://www.perugiasocialphotofest.org/en/english-sina-niemeyer/
} 
La artista sudafricana Alexia Beckerling parte de su propia autobiografía marcada por los abusos sexuales en la infancia, para intentar descubrir su propia identidad: "I observed myself reflected to infinity (of mirrors) and had an unnerving sense of being dissociated from the person I saw. 'Who, in fact, am I?' I wondered"11 (Beckerling, 2004, p.6). Reconocerse y recuperar el contacto con ella misma y con su feminidad la lleva a viajar durante 9 años por distintas culturas del mundo en las que encuentra lugares sagrados con mitologías especiales, transformando el autorretrato en un ritual performativo que le aporta una sensación de pertenencia en el mundo: "The selfportrait allowed me to turn my gaze inwards and overcome being self-conscious. I marked rites of passage on a journey into the self"12 (Beckerling, 2004, p.49). En su libro A Feather in my step $^{13}$ (2004) Beckerling termina afirmando cómo el autodescubrimiento y la aceptación son un viaje que nunca terminan: "It is an ongoing practice, and the vows I made are mantras that need to be repeated: I have come home. I know who I am. I am worthy of love"14 (Beckerling, 2004, p.42). En estos rituales Beckerling utiliza un sombrero de plumas lila, un paralelismo simbólico que comparte el autorretrato Quererse desde un precipicio de Momo (ver Fig. 6). Momo desconocía por completo el trabajo de Beckerling en el momento que tomó esta imagen, y en su caso, utiliza el sombrero de plumas para simbolizar la aceptación de ella misma en el momento presente, con una mirada frontal y penetrante.

La artista catalana Núria Güell plantea en el contexto americano un par de proyectos que incluyen el abuso sexual: Una película de Dios y La feria de las Flores, en la que articula una serie de visitas guiadas a través de las obras en las que Fernando Botero representó el cuerpo femenino, expuestas en la colección permanente del Museo de Antioquia de Medellín. Las guías son menores de edad (entre 12 y 17 años) que han sido explotadas por el creciente negocio del turismo sexual en Medellín.
Para ello, estas atípicas guías de arte moderno se apoyan en sus experiencias personales en torno a la explotación sexual infantil y evidencian la cosificación del cuerpo femenino, mostrando los catálogos de venta de virginidades que circulan por las calles de la ciudad y a través de los cuales los turistas -mayormente procedentes de EE.UU., España, Israel, Alemania y México- seleccionan a la niña o niño cuya virginidad quieren comprar. (Güell, 2015)

La segunda edición de Material sensible ha dado mucho espacio a las visitas comentadas y actividades de divulgación, conducidas por alguna de las participantes del taller y una de las facilitadoras. Las visitas se han orientado hacia la explicación de las vivencias narradas en primera persona con el fin de ampliar la conciencia de cómo el proceso creativo puede ayudar a visibilizar una problemática que ha estado silenciada en la mayoría de los casos. Como nos recuerda la fotógrafa ugandesa Esther Mbabazi, quien utiliza la fotografía y la danza para visibilizar el sufrimiento de las víctimas de la violencia sexual, la sensibilización social es una de las bases de su intencionalidad como artista:

\footnotetext{
11 Me observé reflejada en un infinito (de espejos) y tuve una sensación inquietante de estar disociada de la persona que veía. De hecho, ¿quién soy yo?, me preguntaba. Traducción de la autora.

12 El autorretrato me permitió mirar hacia adentro y superar el hecho de sentirme cohibida. Señalé ritos de paso en un viaje hacia el yo. Traducción de la autora.

13 Una pluma en mi paso. Traducción de la autora.

14 Es una práctica continua, y los juramentos que hice son mantras que necesitan ser repetidos: He vuelto a casa. Sé quién soy. Soy digna de amor. Traducción de la autora.
} 
Creo que el primer paso para la lucha contra este tipo de problemas sociales es la sensibilización. Si nuestras sociedades están sensibilizadas y saben cómo actuar contra ellas, se producirán cambios sustanciales. Si la ciudadanía observa y empatiza con las emociones que muestran mis imágenes, sentirán la necesidad de ayudar a las víctimas de la violencia sexual y también de luchar contra sus perpetradores. (Solés, 2016)

Por otro lado, volviendo a las sesiones de Material sensible, los referentes que se han trabajado en el aula a modo de proyección son artistas que utilizan la cámara como herramienta de diálogo íntimo e identitario, en primera persona, más allá su relación - existente o no - con el ASI. En estas sesiones, se ha contextualizado cada proyecto y a la vez, se ha abierto un espacio para compartir y elaborar los distintos significados, emociones y pensamientos que han emergido de las participantes, alternando momentos de debate y silencio compartido.

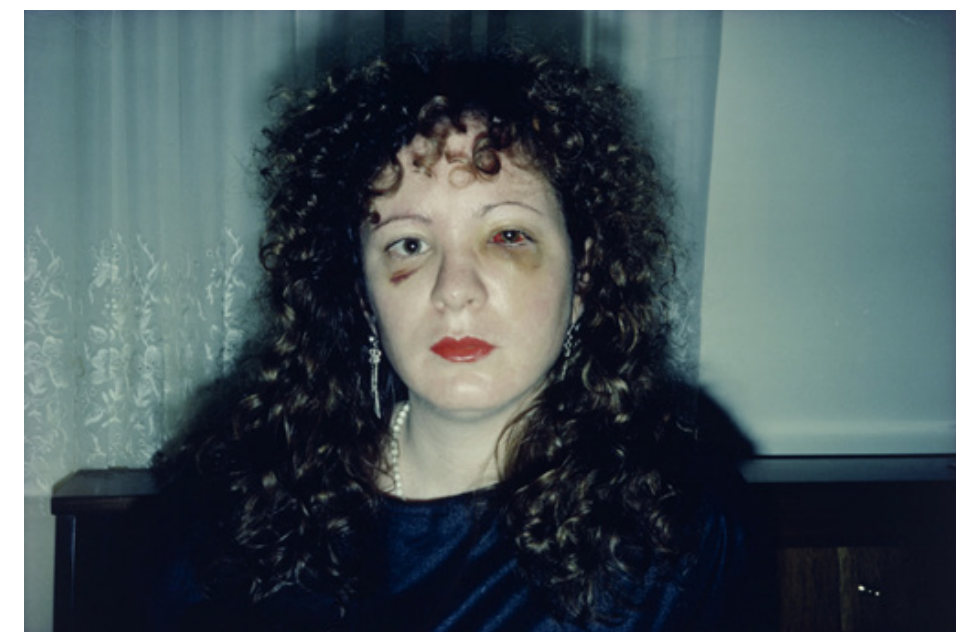

Figura 3. Foto de Nan Goldin, Nan One Month After Being Battered, 1984.

Fuente: MoMA https://www.moma.org/collection/works/102197 (C) 2019 Nan Goldin

Un ejemplo de cómo han influenciado estas sesiones es el caso de Bea, que después de ver y comentar la imagen de Nan Goldin Nan One Month After Being Battered (1984) (ver Fig. 3) volvió la semana siguiente con una serie de cinco autorretratos que más tarde articularon su propuesta expositiva. Las imágenes muestran su evolución personal que va desde el no querer mostrarse, tapándose su rostro con el pelo, pasando por el dolor y la aceptación, hasta la imagen final, en la que consigue dar la vuelta a su historia y mirar directamente a cámara desde un lugar nuevo, lleno de alegría. La imagen de la serie que se muestra a continuación (ver Fig. 4) corresponde a la fotografía central de la serie, en la que consigue mirar directamente a cámara $y$, consigue "una imagen en la que corta con su pasado"15.

15 Bea describe esta imagen (ver Fig. 5) en las visitas guiadas como el momento de cambio en su historia, y acompaña a este autorretrato una foto de un árbol cortado desde la base de su tronco. 


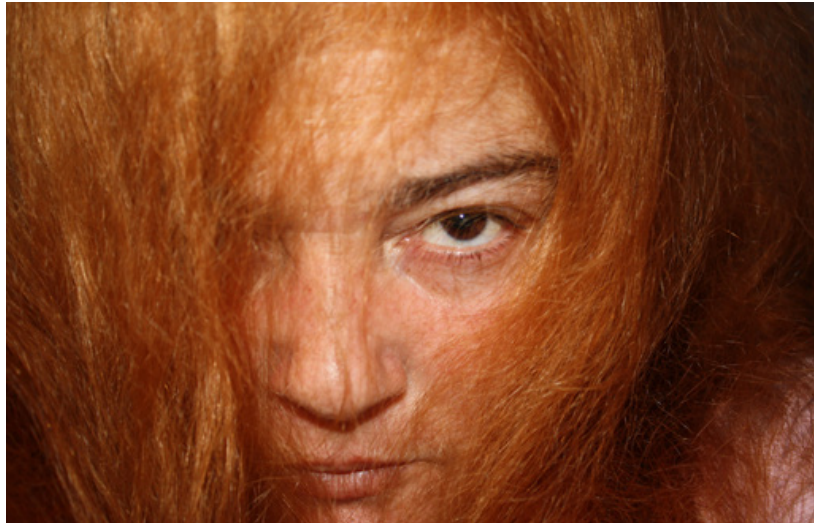

Figura 4. Foto de Bea Baños realizada en la segunda edición de Material sensible, 2019. Fuente: Archivo Punt de Vista, Fundación Photographic Social Vision.

(C) Bea Baños y Fundación Photographic Social Vision.

Otros/as artistas incluidos en estas sesiones de visionados y debate son: Pauline Fargue y sus diarios de bitácora Pages (2012) editados en formato audiovisual que muestran una metodología de creación basada en la cotidianidad; Roman Yñán y sus series fotográficas Life (2007 - 2009) en la que nos enseña cómo crear desde el entorno inmediato, muchas veces sin necesidad de salir de casa, jugando con el encuadre, la luz y utilizando a sus familiares como modelos; o el fotolibro The Bliss of Conformity (2018) de Yingguang Guo, en el que genera un trabajo multidisciplinar de denuncia sobre las visiones estereotipadas de la figura de la mujer en los matrimonios arreglados en China.

Alejándonos un poco del mundo fotográfico, cabe destacar el músico inglés James Rhodes, referente indiscutible de Material sensible, de quien se han utilizado fragmentos de su libro Instrumental (Rhodes, 2015), así como sus interpretaciones y selección de piezas de música clásica citadas en el libro. Estas piezas han acompañado algunos de los ejercicios realizados en las sesiones en el aula, facilitando la conexión entre música, emoción y creación fotográfica.

\section{MÉTODO: LA FOTOGRAFÍA COMO PROCESO DE CREACIÓN}

\subsection{EL PODER DE LA IMAGEN FIJA COMO HERRAMIENTA DE SENSIBILIZACIÓN}

Material sensible ${ }^{16}$ utiliza la fotografía como herramienta que facilita y acompaña un proceso terapéutico utilizando su potencial poético y metafórico. El proceso de creación de la imagen permite expresar simbólicamente emociones, sensaciones y vivencias, articuladas en forma de historias que llegan al espectador de manera sutil o directa. Crear y descifrar una imagen supone hacer uso de partes conscientes e inconscientes de uno mismo, combinando lenguaje verbal y no verbal para otorgar un significado específico de acuerdo con lo que se quiere comunicar. Esta doble vertiente del poder de la imagen permite mostrar de manera directa situaciones, recuerdos o emociones que han quedado a veces bloqueadas o silenciadas y no se podían 
nombrar anteriormente con palabras. Bea ${ }^{17}$ lo explica de manera clara:

A mí, las fotos, me han ayudado a expresar muchas cosas que tenía interiorizadas. He sacado mucho, mucho que tenía escondido. Me ha liberado mucho. Me ha liberado sacar mucho del pasado, mucho odio, mucha rabia, mucha culpa y me ha ayudado a romper con todo ese pasado y conseguir a empezar a ver la vida con más ilusión.

Crear imágenes usando la cámara fotográfica brinda una oportunidad para conectar con uno mismo, haciendo un doble viaje hacia el interior y la propia subjetividad, tomando el espacio exterior, a través de la observación del entorno inmediato que rodea al creador. El fotógrafo debe decidir qué parte del mundo encuadra, así como la lectura que hará de la imagen que ha tomado. Un proceso de significación subjetiva que reafirma la identidad, dando sentido al mundo apropiándote de él y sintiéndote parte de este.

Mireia, participante del proyecto, explica en la evaluación final cómo se siente a la hora de crear imágenes: "hacer fotos me ha servido para ser más consciente de mi mirada. Para mí, es como un estado de meditación en el que mediante lo que hay fuera, conecto mejor conmigo misma".

Un ejemplo de la relación entre la imagen exterior y la vivencia interna es el autorretrato de Beatriz en la playa (ver Fig. 5), que lo realizó respondiendo a un encargo semanal en el que se pedía a cada participante que buscara un lugar en el que se sintiera a gusto haciendo fotos. Beatriz eligió la playa e hizo fotos tranquilamente. Al ver esta imagen impresa en la siguiente sesión, conectó repentinamente con algo que había olvidado: la relación entre el muelle que aparece al final de la imagen y su propio abuso.

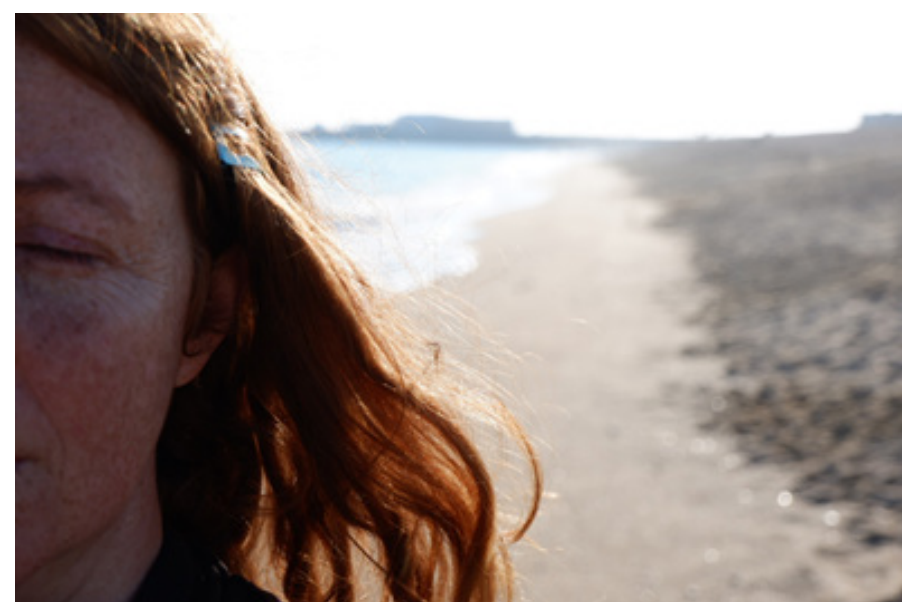

Figura 5. Foto de Beatriz Burgos realizada en la segunda edición de Material sensible, 2019.

Fuente: Archivo Punt de Vista, Fundación Photographic Social Vision.

(C) Beatriz Burgos y Fundación Photographic Social Vision

17 Todas las declaraciones de las participantes del taller que se citan en el presente artículo corresponden a las entrevistas realizadas por Ana de Quadras, mostradas en la segunda exposición de Material Sensible en la galería Chiquita Room (2019). 
Judy Weiser, psicóloga pionera de técnicas fototerapéuticas en Canadá, explica la relación directa entre la imagen tomada del espacio exterior y el relato inconsciente que puede emerger al ver la fotografía: "When we look at photos or artworks we had produced, or review responses to seeing them, and we explore the themes and patterns that emerge when we do so, we are able to learn about our own unconscious". ${ }^{18}$ (Weiser, 1945, p.10)

Es por eso que para editar un conjunto de imágenes disparadas es preciso ordenar y delimitar, hacer un ejercicio de comprensión con la ayuda de la palabra o el texto escrito. Seleccionar qué imágenes son las importantes para exponer, permite poner atención a lo que se quiere a contar a través de ellas. Este ejercicio supone una oportunidad para resignificar la vivencia, con la posibilidad de otorgar un nuevo sentido a lo vivido desde una nueva perspectiva anclada en el presente. Revisar, integrar y digerir la propia historia permite poner distancia y cambiar el punto de vista sobre esta, mecanismo que ayuda a que la persona se dé cuenta del cambio de mirada sobre su historia, y así pueda dar un paso hacia adelante.

En la entrevista expuesta en Chiquita Room (2019), Bea cuenta como utilizó su cuaderno de bitácora, combinando las fotos que había realizado, el álbum familiar y la escritura espontánea, para cambiar su propio relato:

\footnotetext{
Tú escuchas las historias de tus compañeras, pero el click, lo tienes que hacer tú. ¿Cuándo hice yo el click? Pues cuando escribí el libro (...) esparcí todas las fotos y fui eligiendo... y entonces pensé la foto y lo que quería escribir, y ahí hice el click ya de liberarme de todo. De todo. De decir ya basta de comerte la cabeza, de culparte, tú ya no tienes culpa de que te hayan abusado, ahí ya cambié el chip. Y gracias también a la terapia individual y a la terapia de grupo. Pero el libro, me cambió mucho la forma de ver las cosas. Allí dejé toda la mierda, en el libro.
}

Las imágenes nos permiten ver y reconocer una realidad íntima basada en la interpretación subjetiva de quien las observa. Es por eso que la fotografía no solo es un aliado potente que acompaña y enriquece un proceso terapéutico, sino que es una herramienta que, al ser compartida, permite sensibilizar a la sociedad de una temática tabú como es el ASI. El libro de Bea fue expuesto junto con su serie de fotos, y la gente al verlo se sentaba, leía y se emocionaba, tomando conciencia de qué puede suponer pasar por una experiencia como la de ella.

\subsection{DESARROLLO DEL PROYECTO}

Dentro de la fotografía documental contemporánea, una de las características que aportan las dinámicas participativas ${ }^{19}$, es que ubican al protagonista en el lugar de creador y editor de su narración, convirtiéndolo en un "sujeto implicado en el relato de su historia" (Sucari, 2017, p.69). En Punt de Vista, este protagonista - o participante - trabaja con el soporte de un equipo

\footnotetext{
18 Cuando miramos fotos u obras de arte que hemos producido, o revisamos las respuestas que tenemos a verlas, y exploramos los temas y patrones que surgen cuando lo hacemos, podemos aprender sobre nuestro propio inconsciente. 19 Ramón Parramon, artista, profesor y director de proyecto Idensitat, define la participación dentro de las prácticas artísticas contemporáneas como "una manera de hablar de responsabilidad compartida, de activación de las personas, de empoderamiento, de crisis de autoría, de incorporación de la audiencia en la obra, de producción de nuevas relaciones sociales, de construcción en común y de lo común, de la proactividad del espectador emancipado, de las limitaciones del arte y sus necesidades de extradisciplinarse, o de la estetización y escenificación de las relaciones sociales" (Parramon, 2016, p.118).
} 
de. profesionales con perfiles diversos ${ }^{20}$ y una metodología desarrollada a través de la praxis y la revisión constante durante 15 años. Los proyectos Punt de Vista plantean tres preguntas iniciales:

- ¿cómo estructurar un proyecto de fotografía que ayude a personas no profesionales a traducir en imágenes sus realidades?

- ¿cómo facilitar que cada participante exprese de manera gráfica las vivencias, sentimientos, emociones y pensamientos que emergen durante el proceso de creación individual y grupal?

- y finalmente, ¿cómo acompañar el proceso de edición de todas estas imágenes disparadas, con la intención de crear una exposición final de calidad en la que el creador no profesional participe junto a un equipo de profesionales de la fotografía, el diseño, la producción y la comunicación.

Material sensible propone una aproximación desde la delicadeza y el respeto hacia el momento vital de cada persona en el que se enfrenta a la creación de un relato basado en su propia identidad. Para conseguir esta mirada cuidadosa hacia el individuo y su proceso de creación, alejándolo en la medida de lo posible de su rol de víctima, hace falta, también, tener en cuenta un análisis preciso del colectivo con el que se trabaja, el contexto en el que se desarrolla el proyecto y las herramientas que se utilizarán durante todo el proceso de creación, teniendo en cuenta los objetivos que se quieren obtener y la viabilidad de estos. Todas estas características crean la metodología Punt de Vista ${ }^{21}$ que exigen una actitud basada en la práctica y el análisis de ésta, revisando y adaptando constantemente las dinámicas programadas en función de las necesidades del grupo y de los objetivos del proyecto. Una metodología participativa que se fundamenta en acompañar desde la escucha activa a la persona y al grupo, en todas las dimensiones emocionales que se abren al activar un proceso de creación. En Material sensible esta metodología nos ha llevado a combinar espacios de creación con ejercicios individuales y grupales, así como espacios de recogimiento emocional a través de la palabra y la terapia de grupo. Sin olvidar que todas sus participantes, en paralelo al proyecto, han recibido terapia individual.

Cada edición de Material sensible tiene una duración de 20 sesiones de 2 horas cada una, con frecuencia semanal. El proyecto se estructura en cuatro fases distintas: una primera fase de creación de grupo y contacto con la herramienta fotográfica; una segunda en la que se entra en contacto con la intimidad a través de ejercicios pautados que nacen de la conexión entre imagen, memoria, cuerpo y cotidianidad; una tercera etapa en la que durante más de 2 meses las participantes generan sus historias personales creando sus propias narrativas visuales; y una última fase final, que articula la exposición y todo el proceso de comunicación vinculado al proyecto.

Uno de los puntos claves de la metodología utilizada en el taller es que combina fotos individuales

20 Dentro del equipo de facilitadoras del proyecto que trabajan acompañando directamente a las participantes, se encuentran Alice Monteil, antropóloga, terapeuta Gestalt y responsable del Área de Educación de PSV; la autora del texto, fotógrafa, docente e investigadora en la Universidad de Barcelona, colaboradora del Área de Educación PSV; Pilar Polo, psicóloga y responsable de las relaciones institucionales de FVB implicada en la primera edición del proyecto; y en la segunda edición, Núria Grau, psicóloga, terapeuta y mediadora familiar sistémica de FVB..

21 Para más información sobre todos los proyectos Punt de Vista: https://www.photographicsocialvision.org/talleres-punt-devista/ 
hechas libremente por cada participante en su día a día, revisiones grupales semanales de estas imágenes impresas, ejercicios guiados, visitas a exposiciones y ediciones personalizadas. Cada participante dispone de un cuaderno de bitácora para hacer un seguimiento libre de su proceso, así como un ejercicio grupal, basado en compartir en un mural una imagen semanal significativa.

Las participantes llegan al proyecto con diferentes niveles de experiencia en el mundo de la imagen: desde personas semi-profesionales o amateurs, a participantes que jamás han cogido una cámara. Esta diversidad nos obliga a plantear propuestas abiertas con capacidad de evocar utilizando la metáfora y el símbolo. Son actividades basadas siempre en la experiencia directa, que permiten crear imágenes que reconectan emoción, sensación y consciencia, combinando el juego, la técnica fotográfica y la creatividad. Normalmente las fotografías que se toman provienen del entorno que rodea a cada participante, aunque algunas de ellas recorren al álbum de familia o a imágenes tomadas con anterioridad al taller, como es el caso de Momo que llenó su Boîte aux entrailles ${ }^{22}$ de imágenes que ya había realizado anteriormente, pero no se había atrevido nunca a mostrar. Exponerlas suponía una experiencia emocional que le desbordaba y encontró en esta caja llena de agujeros una estrategia para contener su dolor y poder ser vista. Y complementó esta caja con un autorretrato, una mirada llena de firmeza y fuerza titulado "Quererse desde un precipicio" (ver Fig. 6). Momo, lo explica en su entrevista:

Es como cerrar un círculo. No puedo explicar cómo estoy ahora sin que se vea lo qué hay detrás. (...) No soy solo esto, soy muchas más cosas, y por suerte o por desgracia soy también mi pasado, e introducirlo, era muy importante. Que no fuera solo como estoy ahora, sino de dónde vengo. Lo que he hecho para poderlo trabajar bien y cuidarme un poco -porque si no era muy invasivo incluso por mí misma verlo-, ha sido cerrar todo el pasado en una caja, muy protegida, que solo si te acercas y miras por el agujero puedes verlo. Es una caja que no parece que haya dolor adentro, pero lo hay. (...) Y aparte, habrá las fotos de cómo estoy ahora, que es la aceptación de todo esto. Aceptarte a ti mismo con todos los traumas que llevas, como ha influenciado esto y como te puedes llegar a querer, a pesar de tener peculiaridades un poco especiales, o una mirada diferente, y aceptarlo ${ }^{23}$.

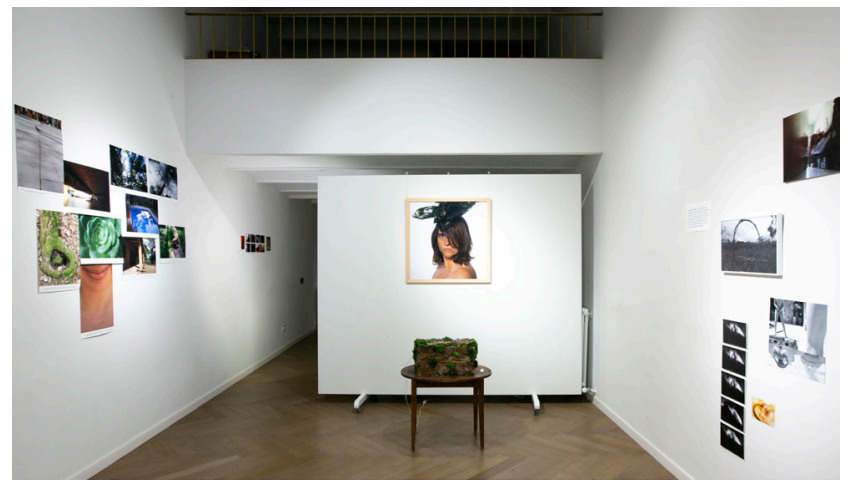

Figura 6. Foto de Mireia Plans con obras de Momo, Mireia M., Isha y Beatriz. Exposición Material sensible en Chiquita Room (2019).

Fuente: Archivo Mireia Plans. @ Mireia Plans y Fundación Photographic Social Vision 
Utilizar las experiencias vitales de las participantes como material creativo con personas que no siempre tienen acceso directo a la educación visual, hace necesaria la figura del facilitador (o facilitadores) que articulen el proyecto comunitario, dando las herramientas necesarias para que la historia pueda llegar al espectador respetando la intencionalidad de cada creador. François Matarrasso considera que en el arte comunitario las figuras del profesional y la del noprofesional deben posicionarse en un mismo nivel, cada una con sus aportaciones específicas al proyecto. Para él, el arte comunitario es "the creation of art as human right, by professional and non-professional artists, cooperating as equals, for purposes and to standards they set together, and whose processes, products and outcomes cannot be known in advance"24 (Matarrasso, 2019, p.51).

Material sensible no es un proyecto fototerapéutico en sí, ya que no utiliza la fototerapia como finalidad, sino que pone el foco en el proceso de creación artística, atendiendo a las necesidades emergentes de cada uno/a. Weiser hace hincapié en la diferencia entre un proceso terapéutico realizado con técnicas de fototerapia, de un proyecto de acción social que utiliza técnicas procedentes de la fotografía terapéutica para generar cambios a nivel personal y social:

In contrast with PhotoTherapy techniques - which are therapy practices - Therapeutic Photography techniques are photographic practices, where the intended goal is to produce positive change in individuals, couples, or families, but they also include broader Social Action Photography techniques where the goal is to improve well-being, reduce social exclusion, and create positive change at community, societal, national, or international levels. ${ }^{25}$ (Weiser, 1993)

Uno de los objetivos de Material sensible ha sido crear un clima de confianza necesario para que las participantes pudieran expresarse libremente y sintieran siempre sus propios límites respetados sobre lo que querían mostrar o exponer. Isha, participante del proyecto, explica en su entrevista cómo la fotografía es un espacio donde nadie la juzga, nadie le dice nada, y puede pararse y pensar en ella. Bea, compañera de Isha, comenta que las fotos le ayudan a expresar emociones y a desprenderse de su pasado. En una primera fase ella volcó en una libreta todo lo que tenía por contar y no había explicado nunca. Las fotos de su álbum familiar le ayudaron a explicar de manera clara y concisa su historia. En paralelo, cogía la cámara y salía a fotografiar:

Cuando hago fotos me aíslo, me meto en mi mundo y ya puede pasar gente que ni la veo. Miro, me gusta ir a Montjuïc a hacer las fotos, conecto con la naturaleza, me siento llena de paz y me libero. Me dejo llevar. Y entonces, cuando veo algo que me llama mucho la atención pues le hago la foto. No es que las busque, me llaman ellas a mí.

Bea ha conseguido dar un doble uso a la fotografía: como revisión y resignificación de su pasado, y como creación de una nueva realidad que rodea su día a día. Tan importante ha sido para ella revisitar y reordenar lo vivido, como anclar y tomar nota de la transformación que se ha asomado en el presente. En este caso, tanto la fotografía como la escritura han sido las mejores herramientas para reconstruir y aceptar quien es hoy y de donde viene. Estos cambios han

24 La creación del arte como un derecho humano, por artistas profesionales y no-profesionales, cooperando como iguales, con fines y estándares que establecen juntos, y cuyos procesos, productos y resultados no pueden ser conocidos de antemano. Traducción de la autora.

25 En contraste con las técnicas de Fototerapia - que son prácticas terapéuticas - las técnicas de Fotografía Terapéutica son prácticas fotográficas, donde el objetivo previsto es producir un cambio positivo en individuos, parejas o familias, pero también incluyen técnicas de Fotografía de Acción Social más amplias en las que el objetivo es mejorar el bienestar, reducir la exclusión social y crear cambios positivos a nivel comunitario, social, nacional o internacional. Traducción de la autora. 
afectado también a su entorno ya que, gracias a la fotografía, Bea consiguió decírselo a su hijo. "Fue muy bonito, porque sin la fotografía yo nunca no se lo hubiera podido decir a mi hijo, así, en una conversación, porque yo no tenía valor de decírselo con palabras".

\subsection{EXPOSICIÓN FINAL}

Como resultado final y cierre de la edición de cada proyecto, se han creado dos exposiciones en las galerías de arte contemporáneo Projekteria [Art Gallery] (2017) y Chiquita Room (2019). Generar un producto artístico de calidad para conseguir cierto impacto en el público es uno de los objetivos internos conseguidos en ambas ediciones. Los comentarios recibidos por parte de los visitantes, las reacciones de los grupos durante las visitas guiadas y la aparición del proyecto en los medios de comunicación son una muestra de la buena acogida que ha tenido Material sensible.

El momento de exponer implica un reto delicado y decisivo, al sumar los conocimientos de los profesionales y los no-profesionales, que apunta Matarasso, y que requiere mantener el espacio de confianza, respeto y cuidado creado a lo largo del proceso, respetando en todo momento la última palabra de las protagonistas y sus historias. Es importante como profesionales entender que acompañar sin juzgar refuerza el sentimiento de pertenencia de la obra a la persona que la ha creado. Muchas participantes destacan en las evaluaciones finales no haberse sentido juzgadas durante el proceso. A la pregunta de qué es lo que más valora del taller, Mireia, participante del proyecto, responde en la evaluación final: "No haberme sentido juzgada. Haberme sentido acompañada, con sensibilidad, sin condescendencia y con afectuosidad tanto por parte de las talleristas como las compañeras y las colaboradoras que han venido puntualmente a las sesiones".

Las exposiciones finales, diseñadas ambas por Inés Casals ${ }^{26}$, ayudan a dar cuerpo y ubicar en los espacios expositivos las series creadas por las participantes, incluyendo las piezas videográficas ${ }^{27}$ realizadas por Ana de Quadras ${ }^{28}$ basadas en entrevistas a las autoras que se sienten preparadas para dejar su testimonio cara a cara.

Parte de estas piezas audiovisuales se distribuyen en las redes junto con los textos, creados por Laura González ${ }^{29}$, que articulan la campaña de comunicación diseñada desde PSV y que pretende incidir en la sensibilización de la problemática y la promoción del proyecto en sus distintas fases.

Cuando el resultado se muestra al público y las participantes consiguen explicar con imágenes el recorrido emocional de la historia vivida, incidiendo en la toma de consciencia que cada persona ha hecho a lo largo del proceso de creación - sin necesidad de contar los detalles de lo que pasó durante el abuso-, finaliza parte el proyecto. En esta última fase acontecen la inauguración, entrevistas con la prensa, coloquios y visitas guiadas a grupos. Actividades lideradas por las

26 Inés Casals es diseñadora especializada en fotografía contemporánea y ha realizado el diseño gráfico de ambas exposiciones de Material sensible, participando en algunas sesiones del proceso de creación junto con las participantes y el equipo de profesionales de PSV.

27 Las piezas audiovisuales de las dos ediciones de Material sensible se pueden visualizar en: https://youtu.be/psqtz9xINoU (2017) y https://youtu.be/PjYhLuTCQFU (2019).

28 Ana de Quadras es productora audiovisual y docente, ha realizado varias piezas audiovisuales que acompañan el proyecto, incluidas en la exposición de la segunda edición de Material Sensible y en ambas campañas de comunicación.

29 Laura González es periodista y fundadora de Chiquita Room, ha participado en la comunicación del proyecto. 
protagonistas junto con las profesionales que las acompañan. Y aquí no todas las participantes quieren o pueden participar. Es un momento delicado que precisa mucha escucha por parte de todas ya que en todo momento ellas deciden como, cuando y de qué manera quieren exponerse.

Esta exposición final añade cierta presión durante el proceso de creación, pero las actividades que la acompañan son una oportunidad para integrar la mirada del otro que ayuda a fijar la experiencia vivida y genera un vínculo entre las participantes y los espectadores, aumentando la autoestima, el sentimiento de pertenencia, la aceptación y la inclusión en la sociedad.

En palabras de la periodista Natàlia Farré en su artículo publicado a raíz de la exposición en Chiquita Room (2019):

Material sensible es relevante como experiencia vital para las cinco mujeres, pero es también un mensaje para las muchos y muchas víctimas que no denuncian ni piden ayuda. (...) La exposición interpelará a mucha gente, pero sobre todo a esas personas que necesitan apoyo: "han de pensar que se puede salir del pozo", afirma una de las cinco (autoras), no importa cuál. La misma que apunta: "Exponer supone un gran paso, ya que el abuso es un secreto a voces. Prácticamente todos lo saben, pero nadie dice nada, entonces ¿por qué debo seguir ocultándolo? Me gusta este proyecto, me siento muy orgullosa del trabajo y quiero enseñarlo, no para mí, sino para todos y todas". (Farré, 2019) 


\section{Consideraciones finales}

Más allá del acompañamiento terapéutico a personas que han sufrido abusos sexuales en la infancia, la fotografía actúa como una herramienta de creación metafórica que permite simbolizar y nombrar la experiencia vivida, acelerando el proceso de reconstrucción de la identidad. Trabajar la imagen vinculada a la historia de vida, abre la posibilidad de relatar desde otro ángulo la propia experiencia, reconociéndola, y en el mejor de los casos, permitiendo la desidentificación con el rol de víctima.

Poner foco en la experiencia vivida utilizando la fotografía sirve como excusa para entrar en contacto con uno/a mismo/a. El poder que tiene la imagen para transmitir emociones y contar historias de vida, no solo es un aliado potente que acompaña y enriquece un proceso terapéutico, sino que es una herramienta que permite sensibilizar a la sociedad sobre temáticas que quedan silenciadas como es el ASI. El impacto que generan estos relatos en primera persona con el público que asiste no solo a la exposición sino a las actividades complementarias donde las autoras y profesionales pueden transmitir la experiencia vivida, justifica la necesidad de impulsar proyectos artísticos que trabajen la individualidad desde la comunidad, ayudando a rehacer redes de contacto entre iguales y personas afines.

La inclusión de los artistas no-profesionales en el arte contemporáneo, precisa de la formación de equipos de trabajo mutidisciplinares que enriquezcan exponencialmente los procesos de creación artística contemporánea. Incidir en el capital cultural y social actual es una de las funciones del arte contemporáneo, facilitando su difusión y democratización de nuestro entorno cultural. 


\section{Bibliografía}

Baita, S. y Moreno, P. (2015). Abuso sexual infantil: Cuestiones relevantes para su tratamiento en la justicia. Montevideo, Uruguay: UNICEF, CEJU, Fiscalía General de la Nación. Recuperado de http://www.bibliotecaunicef.uy/doc_num.php?explnum_id=141

Bernadet, V. (2016). La confianza educada. Madrid, España: TEDxTalks. Recuperado de https://youtu.be/Gqw0IQc1mRw/

Crisma, M., Bascelli E., Paci, D. y Romito, P. (2004). Adolescents who experienced sexual abuse: fears, needs and impedimeents to disclosure. Child Abuse \& Negleet, 28, 1035-1048. Recuperado de https://www.sciencedirect.com/science/article/abs/pii/ S0145213404002005

Echeburúa, E. y Guerricaechevarría, C. (2000). Abuso sexual en la infancia: víctimas y agresores. Madrid, España: Ariel.

Farré, N. (7 de noviembre de 2019). Disparar contra la culpa, el miedo y la vergüenza. El Periódico de Catalunya. Recuperado de https://www.elperiodico.com/es/barcelona/20191107/material-sensible-disparar-contra-la-culpa-el-miedo-y-la-verguenza-7717199

Furrer, M. (2014). My piece of sky. Johannesburgo, Sudáfrica: Mariella Furrer.

Güell, N. (2015,16). La feria de las flores. Medellín, Colombia: s/n. Recuperado de http://www.nuriaguell.net/projects/41.html

Kempe, H., Silverman, F., Steele, B., Droegemueller, W. y Silver, H. (1962). The Battered Child Syndrome. Jounal of the American Medical Association, 181, 17-24. Recuperado de https:// jamanetwork.com/journals/jama/article-abstract/327895/

López, F. (1996). Abusos sexuales a menores. Lo que recuerdan de mayores. Madrid, España: Ministerio de Trabajo y Asuntos Sociales.

Maillard, C. (2014). La baba del caracol. Madrid, España: Vaso Roto Cardinales.

Matarrasso, F. (2019). A restless Art. London, United Kingdom: Calouste Gulbenkian Foundation.

NCTSN (2009). Folleto informativo sobre el abuso sexual infantil: 
Para padres, maestros y demás cuidadores. Los Ángeles, EUA. The National Child Traumatic Stress Network. Recuperado de https:// www.nctsn.org/resources/folleto-informativo-sobre-el-abusosexual-infantil-para-padres-maestros-y-demas-cuidadores/

Niemeyer, S. (2018). Für mich. Cologne, Alemania: Ceiba Editions en colaboración con The PhotoBook Museum.

Parramón, R. (2019). Estéticas de la colaboración. Intermediaciones entre lo colectivo, lo participativo y lo colaborativo en las prácticas artísticas sistémicas. En D'anada i tornada. Projectes $i$ pràctiques col/laboratives des del museu a través de l'art. (pp. 114-122). Palma de Mallorca, España: Fundació Es Baluard.

Pereda, N. y Forns, M. (2007). Prevalencia y características del abuso sexual infantil en estudiantes universitarios españoles. Child Abuse \& Negleet, 31, 417-426. Recuperado de https://www. slideshare.net/elmundodelosasi/prevalencia-y-caractersticasdel-abuso-sexual-infantil-en-estudiantes-universitarios-espaolespereda-forns-2007

Rhodes, J. (2015). Instrumental. Barcelona, España: Blackie Books.

Royo, R (2016). Sufrir A.S.I. Temas de psicoanálisis. Sociedad Española de Psicoanálisis (12). Recuperado de http://www. temasdepsicoanalisis.org/2016/07/30/sufrir-a-s-i/

Solés, G. (2016). Esther Mbabazi dispara al dolor del abuso. El País. Recuperado de https://elpais.com/elpais/2016/10/31/ planeta_futuro/1477933147_169961.html

Sucari, J. (2017). El documental social participativo: el protagonista como sujeto de la historia. Obra Digital, (12), 69-85. Recuperado de https://doi.org/10.25029/od.2017.112.12

Tardieu, A. (1878). Étude Médico-Légale sur les Attentats aux Moeurs. París, Francia: Librairie J.-B.-Bailliere et fils. Recuperado de https://gallica.bnf.fr/ark:/12148/bpt6k9785629t.textelmage

Torres, M. (2018). Abuso sexual infantil (ASI). Re, revista de pensamiento y opinión. Recuperado de https://www.revistare. com/2018/l 1/abuso-sexual-infantil-asi/

Weiser, J. (1945). PhotoTherapy Techniques: Exploring the Secrets of Personal Snapshots and Family Albums. Vancouver, Canada: Photo Therapy Center Publishers.

Weiser, J. (1993). Therapeutic Photography. Vancouver, 
Canada: s/n. Recuperado de https://phototherapy-centre.com/ therapeutic-photography/ 